\section{Contraception e-learning for medical students}

Historically, topics related to family planning have not been comprehensively covered in undergraduate medical education. While the Association of Professors of Gynecology and Obstetrics (APGO) guidelines for medical education include topics related to contraception, surveys of residents have demonstrated low baseline levels of knowledge regarding this topic. ${ }^{12}$ As physicians in many different specialities may counsel patients about and prescribe contraception, undergraduate medical education provides a key setting for acquiring this information.

Medical education traditionally relies on in-person lectures as the core component of teaching, yet audio and video podcasts are increasingly being used as supplemental resources. Surveys of trainees have shown that podcast learning is at least equally effective as lecture-based learning or independent reading as regards knowledge acquisition and retention. ${ }^{3-5}$ There are currently few educational-based podcasts aimed at medical students covering the topic of contraception; the development of such a podcast has the potential to improve knowledge among students.

We created an audio and video podcast ('vodcast') for medical students at the University of California Los Angeles. APGO Educational Objectives were used as a framework for the script, focusing on the types of contraception as well as their efficacy, mechanism of action, contraindications and side effects. ${ }^{1}$ The podcast featured a conversational-style lecture between two family planning faculty members, while the vodcast featured a family planning faculty member with accompanying slides. Both were $28 \mathrm{~min}$ in length.

Third-year medical students completing their Obstetrics \& Gynaecology $(\mathrm{OB} / \mathrm{GYN})$ clerkship during the 2019-2020 academic year were invited to participate, and alternating cohorts received either the podcast or vodcast. Pre-surveys were distributed to assess baseline experience with podcasts, participant demographics and subjective contraception knowledge. Students then received their assigned educational intervention via a shareable link. After

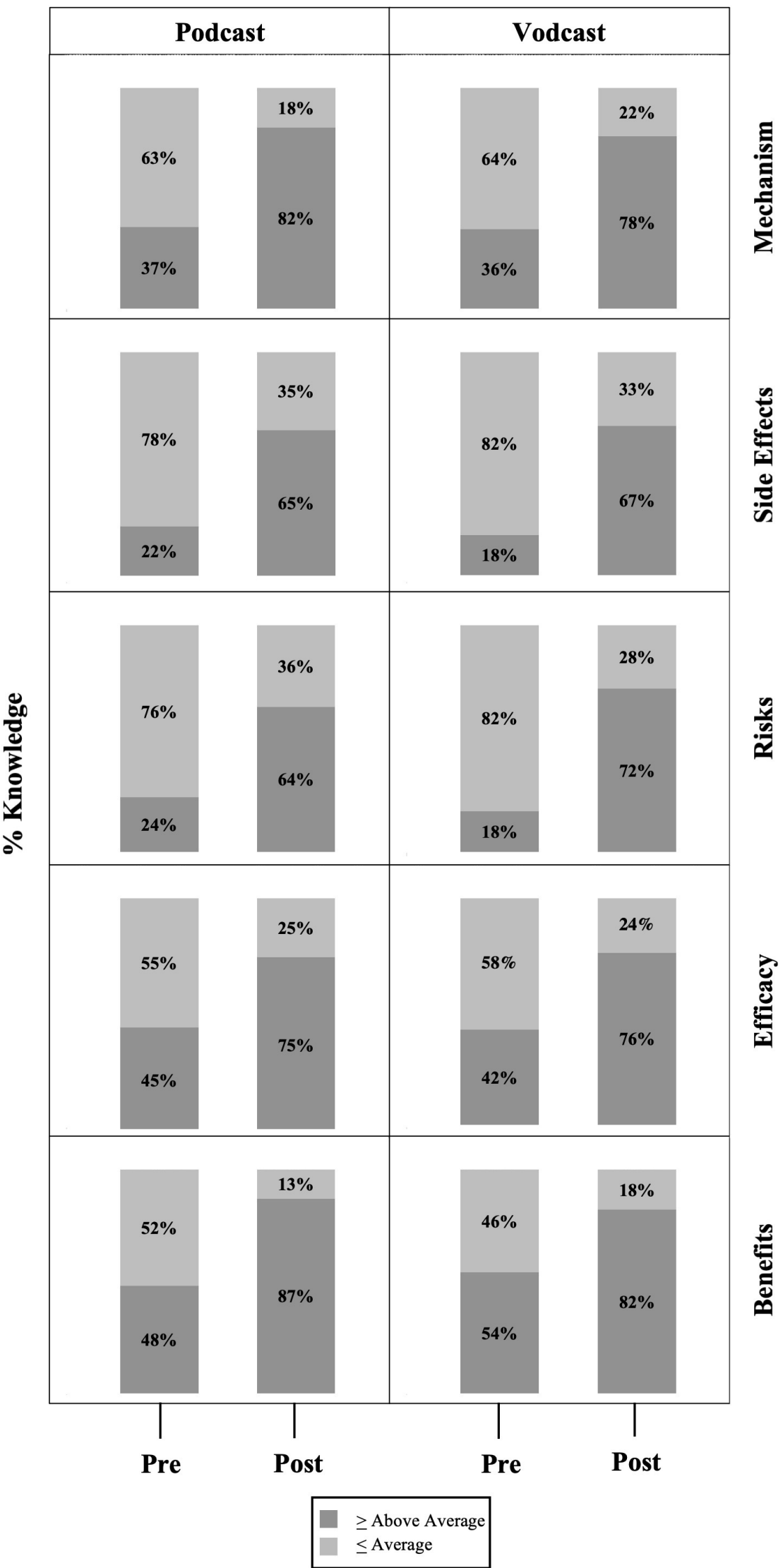

Figure 1 Knowledge assessment pre-intervention versus post-intervention by podcast and vodcast. "Average or less" includes students that rated knowledge as "poor", "below average" or "average", while "above average or greater" includes students that rated knowledge as "above average" or "excellent" ( $p<0.001$ for each group). 
listening to the podcast or viewing the vodcast at least once, students were asked to complete an electronic postsurvey which measured subjective knowledge as well as satisfaction with and usefulness of the learning tool. All responses were anonymous.

Eleven separate cohorts participated in the study (five podcast, six vodcast). A total of 183 students participated (89 podcast, 94 vodcast). Some $63 \%$ in the podcast group and $91 \%$ in the vodcast group completed the activity (submission of post-surveys after using the educational intervention at least once). Demographics were similar between the groups. There was no difference in selfrated contraceptive knowledge between the groups pre-intervention.

After using the educational tools, $81 \%$ of students in the podcast group and $84 \%$ in the vodcast group rated the interventions "very useful" or "extremely useful" ( $p=0.6492)$. There was no difference in satisfaction between the groups and no difference in intention to recommend the method to others. Subjective knowledge increased significantly post-intervention regarding available methods of contraception, efficacy, mechanism of action, contraindications and the side effects of contraception, and was not different between groups (figure 1).

Third-year medical students completing their $\mathrm{OB} / \mathrm{GYN}$ clerkship found both our podcast and vodcast to be acceptable and useful teaching tools. Students reported subjectively increased knowledge regarding important topics related to contraception, and the majority of students reported being extremely satisfied with the learning methods. While e-learning modules have shown promise among medical students and residents in various specialties, this represents one of only a few covering the topic of contraception. With the increased need for distanced learning due to the COVID-19 pandemic, audio and video learning represent an increasingly important adjunct to traditional teaching. In our programme, additional podcasts covering other topics in $\mathrm{OB} /$ GYN are being developed in order to better facilitate remote learning, and feedback from this cohort is being used in order to improve the experience for future students.

\section{Krista Marie Douglass $\odot{ }^{1}$, Clarissa Niino, ${ }^{1}$ Karen Bryan, ${ }^{1}$ Lorna Kwan, ${ }^{2}$ Aparna Sridhar ${ }^{1}{ }^{1}$}

'Department of Obstetrics \& Gynecology, University of California Los Angeles, Los Angeles, California, USA

${ }^{2}$ Department of Urology, University of California Los Angeles, Los Angeles, California, USA

Correspondence to Aparna Sridhar, Department of Obstetrics \& Gynecology, University of California Los Angeles, Los Angeles, USA; ASridhar@ucla.mednet. edu

Contributors KMD, CN, KB and AS planned the study, designed the surveys, and created the educational tools. LK performed statistical analysis. KMD and AS drafted the manuscript. KMD, CN, $\mathrm{KB}$, AS and LK reviewed and approved the final version of the manuscript. KMD submitted the study.

Funding The authors have not declared a specific grant for this research from any funding agency in the public, commercial or not-for-profit sectors.

Competing interests None declared.

Patient and public involvement Patients and/or the public were not involved in the design, or conduct, or reporting, or dissemination plans of this research.

Patient consent for publication Not applicable.

Ethics approval This study involved human participants but it was granted exemption by the University of California Los Angeles Institutional Review Board (IRB\#20-001258). Participants gave informed consent to participate in the study before taking part.

Provenance and peer review Not commissioned; internally peer reviewed.

(c) Author(s) (or their employer(s)) 2021. No commercial re-use. See rights and permissions. Published by BMJ.

\section{Check for updates}

BMJ Sex Reprod Health 2021;0:1-2. doi:10.1136/bmjsrh-2021-201401

\section{ORCID iDs}

Krista Marie Douglass http://orcid.org/ 0000-0002-1987-8409

Aparna Sridhar http://orcid.org/00000003-0813-9130

\section{REFERENCES}

1 Association of Professors of Gynecology and Obstetrics (APGO). APGO medical student educational objectives, 10th edn, 2014. Available: https://obgyn. msu.edu/images/communities/resources/ APGO $\% 20$ Med $\% 20$ Student $\% 20$ Obj $\%$ 2010\%20Ed\%20.pdf [Accessed Dec 2020].

2 Miller M, Marengo A. Basic knowledge of contraception and emergency contraception is low among recent medical school graduates. Obstet Gynecol 2018;132:37S-8.

3 Raupach T, Grefe C, Brown J, et al. Moving knowledge acquisition from the lecture hall to the student home: a prospective intervention study. J Med Internet Res 2015;17:e223.

4 Childers RE, Dattalo M, Christmas C. Podcast pearls in residency training. Ann Intern Med 2014;160:70.

5 White JS, Sharma N, Boora P. Surgery 101: evaluating the use of podcasting in a general surgery clerkship. Med Teach 2011;33:941-3. 